
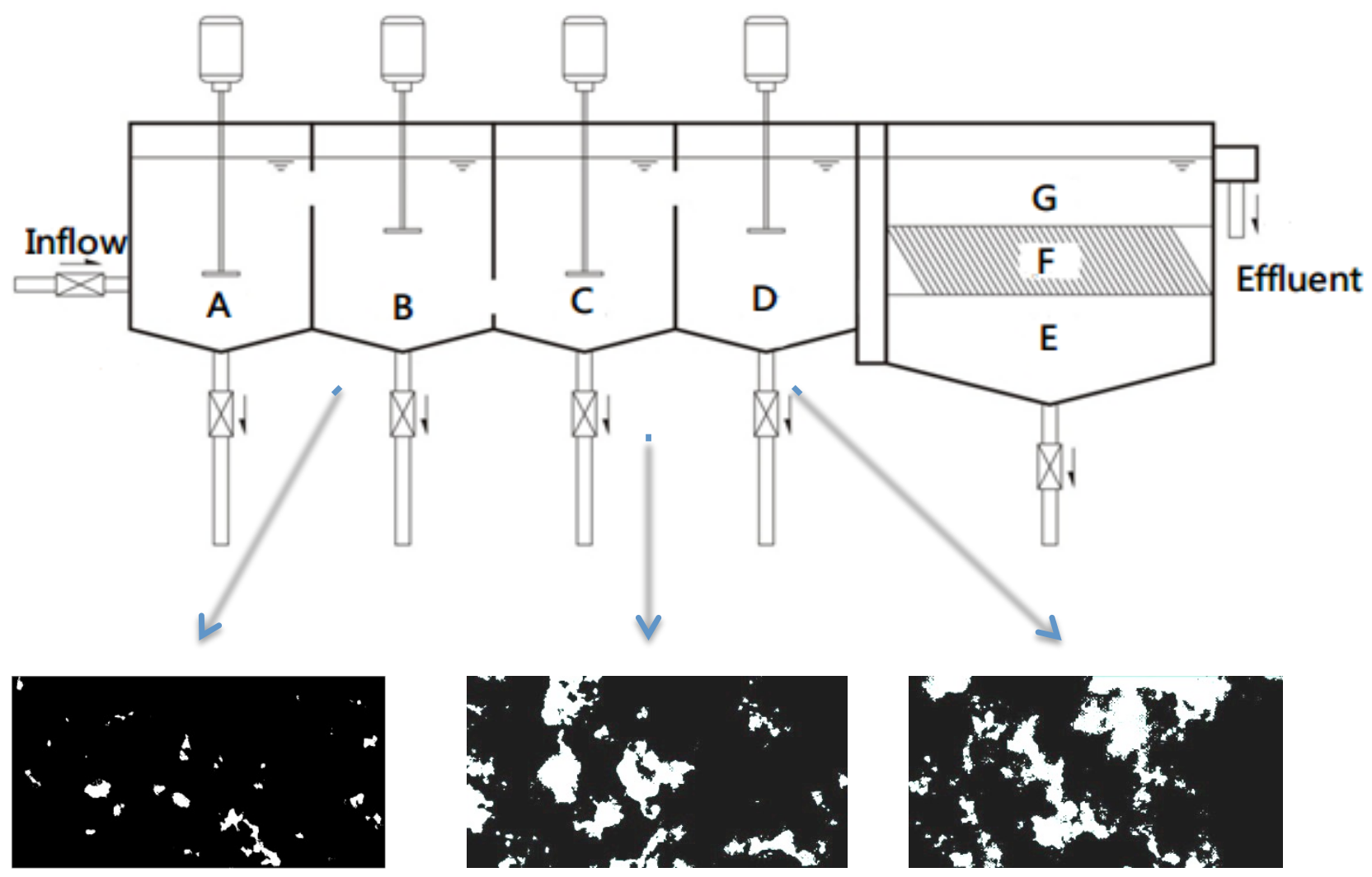


\title{
Analysis of floc morphology in a continuous-flow flocculation and sedimentation reactor
}

Pengfei Ren ${ }^{1}$, Jun Nan ${ }^{1,2, *}$, Xinran Zhang ${ }^{1}$, Kai Zheng ${ }^{1}$

\begin{abstract}
The floc morphology was investigated in a continuous-flow reactor, in order to understand the evolution of flocs in practical flocculation and sedimentation processes in water utilities. Kaolin-humic acid suspension was used as the test water, and polyaluminum chloride was chosen as the coagulant. An in-situ recognition system was applied to analyze the floc size, boundary fractal dimension, and eccentricity ratios. Particle numbers and turbidity were also determined in the sedimentation stage. At a coagulant dose of $1 \mathrm{mg} / \mathrm{L}$ as $\mathrm{Al}$, the average floc size increased from 62 to $78 \mu \mathrm{m}$ and the boundary fractal dimension was around 1.14, suggesting that flocs were compact and continuously grew during the entire flocculation process. However, with the dose increased to $5 \mathrm{mg} / \mathrm{L}$, the average floc size decreased and stabilized at around $65 \mu \mathrm{m}$, with the fractal dimension of 1.20 . It can be concluded that the excess coagulant doses resulted in the formation of chain-shaped, lower density, and more branched structure flocs, thereby restricting flocs' further growth in the subsequent flocculation. Floc morphology analysis suggested that charge neutralization dominated in the initial flocculation stage, then the bridge and sweep mechanisms were dominant in the subsequent flocculation. In addition, compared with the traditional inclined plate settler, a novel V-shaped plate settler introduced in this study had an advantage in small size floc (less
\end{abstract}


than $5 \mu \mathrm{m}$ ) removal. The $\mathrm{V}$-shaped region could promote aggregate restructuring and re-flocculation; therefore, the V-shaped plate settler provides an alternative method for sedimentation.

Keywords: Flocculation, sedimentation, continuous-flow reactor, in-suit recognition system, V-shaped plate settler tank

\section{Introduction}

Flocculation and sedimentation are the most common processes for particle and colloid removal, which have been considered to be the first step in drinking water treatments (Jarvis et al., 2005; Wang et al., 2011). In previous studies, flocculation conditions (such as coagulant types, coagulant doses, mixing intensity, and $\mathrm{pH}$ value) have been extensively investigated in order to improve flocculation efficiency (Shin and Sobsey, 2015; Zhao et al., 2013; Hua et al., 2014)

It should be noted that floc characteristics also play important roles in flocculation. Flocs undergo the growth stage, breakage stage, restructuring stage, and finally achieve stability with a balance of aggregation and breakage (Gmachowski, 2009; Nan et al., 2011; Nasser, 2014). Floc characteristics (such as floc size, structure, and strength) change continuously in these flocculation stages. Previous studies have confirmed that floc structures have a significant impact on flocculation efficiency (Nan et al., 2009; Vandamme et al., 2014). For instance, aggregates that are highly porous and loose are susceptible to breakage and difficult to settle, and vice versa (Kim et al., 2013). Furthermore, analyses of floc characteristics have also been applied to investigate the effect of floc breakage in the coagulation/ultrafiltration process (Yao et al., 2015), as well as the influence of coagulant dose on the process (Yao et al., 2015).

Numerous flocculation studies have been conducted in jar tests (Li et al., 2014; Yu et al., 
2011; Yang et al., 2014). Although jar tests can predict the behavior of flocculation processes in many cases, the jar-test method can merely reflect the final status of flocs. It has been confirmed that the hydraulic conditions impose an important influence on floc characteristics in flocculation and further affect the purification efficiency (He et al., 2012). However, the hydraulic conditions of flocculation in practical water utilities cannot be effectively simulated in jar tests. In addition, flocs generated during flocculation can directly impact sedimentation efficiency (Becker et al., 2009). Therefore, it is more feasible to apply a continuous-flow reactor for an integrated understanding of the floc evolution in flocculation and sedimentation process.

Based on the fact that flocculation and sedimentation are complicated and chaotic processes, a continuous-flow reactor is necessary to simulate the practical flocculation and sedimentation process in water utilities. However, few studies have been conducted in such reactors. To the best of our knowledge, the evolution of floc characteristics in a continuous-flow flocculation and sedimentation reactor has never been reported. In order to clarify these problems, this study for the first time systematically monitors and analyzes the evolution of floc characteristics in a continuous-flow flocculation and sedimentation reactor, thereby reflecting floc status in practical flocculation and sedimentation processes in water utilities to a greater extent.

This study concerns the evolution of flocs in a continuous-flow reactor that contains four flocculation tanks and one settler tank. A synthetic kaolin-humic acid suspension was used as the test water sample. The investigation focuses on the floc characteristics, in terms of the average floc size, boundary fractal dimension, and eccentricity ratios. In addition, a novel V-shaped plate settler was designed in order to improve the sedimentation efficiency. The particle numbers and effluent turbidity were measured to evaluate and compare the efficiency of the V-shaped plate settler and a traditional inclined plate settler.

\section{Material and methods}

\subsection{Kaolin-humic acid suspension}


Kaolin solution was prepared by dissolving $1.80 \mathrm{~g}$ of kaolin (Tianjin, China) with $1 \mathrm{~L}$ tap water. In order to obtain a sufficiently dissolved kaolin solution, the $\mathrm{pH}$ of the solution was adjusted to 12 using $2 \mathrm{~mol} / \mathrm{L} \mathrm{NaOH}$. The solution was mixed at $1000 \mathrm{r} / \mathrm{min}$ for $60 \mathrm{~min}$ by a stirrer and then placed in the dark for $24 \mathrm{hr}$. Humic acid solution was obtained by dissolving $36 \mathrm{mg}$ of humic acid (Shanghai, China) in $0.1 \mathrm{~mol} / \mathrm{L} 200 \mathrm{~mL}$ of $\mathrm{NaOH}$. The solution was filtered by a $0.45 \mu \mathrm{m}$ fiber filter membrane. The kaolin-humic acid suspension was a mixture of the kaolin solution and humic acid solutions. The $\mathrm{pH}$ of the solution was adjusted to 7.2 using $0.1 \mathrm{~mol} / \mathrm{L} \mathrm{NaOH}$ and $0.1 \mathrm{~mol} / \mathrm{L} \mathrm{HCl}$. The preparation process had been successfully used in our previous study (He et al., 2012).

\subsection{Apparatus}

In order to simulate practical flocculation and sedimentation processes in drinking water utilities, a continuous-flow reactor was used in this study. As shown in Fig. 1, the flocculation section consisted of four equal pools, named pool A, pool B, pool C and pool D. The volume of each pool was $12.5 \mathrm{~L}(\mathrm{~L} \times \mathrm{W} \times \mathrm{H}=250 \mathrm{~mm} \times 250 \mathrm{~mm} \times 200 \mathrm{~mm})$. Synthetic test water flowed through pool A to pool D and sequentially flowed into an up-flow settling tank. The total volume of the up-flow settler was $81 \mathrm{~L}(\mathrm{~L} \times \mathrm{W} \times \mathrm{H}=450 \mathrm{~mm} \times 600 \mathrm{~mm} \times 350 \mathrm{~mm})$. The settling tank was divided into three parts, named unit E, unit F, and unit G, respectively. Two kinds of plates were installed in unit F, corresponding to a traditional inclined plate sedimentation tank and a novel V-shaped plate sedimentation tank.

Fig. 2 illustrates a cross-sectional view of the V-shaped plate and traditional inclined plate. Both of the plates had an inclined plate section, whereas the V-shaped plate had an additional V-shaped region. The intervals of the inclined plate section in the two kinds of plates were $5 \mathrm{~mm}$, with a 60 -degree angle. In the V-shaped region, the minimum interval was $5 \mathrm{~mm}$ with the angle of 60 degrees. The height of the inclined plate region was $100 \mathrm{~mm}$, whereas, the V-shaped plate had a total height of $120 \mathrm{~mm}$ including $80 \mathrm{~mm}$ height for the inclined plate region and $40 \mathrm{~mm}$ height for the $\mathrm{V}$-shaped region. 


\subsection{Procedure}

The kaolin-humic acid suspension was mixed with tap water (Harbin, China). The tap water contained total alkalinity of $108 \mathrm{mg} / \mathrm{L}$ as $\mathrm{CaCO}_{3}$ and hardness of $152 \mathrm{mg} / \mathrm{L}$ as $\mathrm{CaCO}_{3}$ with conductivity of $492 \mu \mathrm{S} / \mathrm{cm}^{2}$. The experimental water contained around $100 \mathrm{mg} / \mathrm{L}$ of kaolin and $2 \mathrm{mg} / \mathrm{L}$ of humic acid. The $\mathrm{pH}$ of the experimental water was around 7.3-7.8. The initial turbidity of the test water samples was $100 \pm 5$ NTU, measured by an online turbidity meter (700AQ, WTW, Germany). The experimental water was directly pumped into the inflow pipe of the continual-flow reactor.

Polyaluminum chloride (PACl, 1\%, W/W, Tianjin, China) was used as the coagulant in this study. According to experimental conditions, a certain amount of $\mathrm{PACl}$ was directly pipetted by a metering pump (D25RE2, Dosatron, France) into the inflow pipe near the inlet of the continual-flow reactor to achieve the desired $\mathrm{PACl}$ concentration.

The experimental water sequentially flowed through the four pools in the flocculation section with a flow rate of $2 \mathrm{~L} / \mathrm{min}$. In pool $\mathrm{A}$, the experimental water and coagulants were adequately mixed, with a relatively high shear rate of $548 \mathrm{sec}^{-1}$. The shear rate was

successively reduced to $69 \mathrm{sec}^{-1}$ for pool B, $32 \mathrm{sec}^{-1}$ for pool C, and $15 \mathrm{sec}^{-1}$ for pool D, respectively. The gradual decreasing trend of shear rates was consistent with practical water utilities. Then, water samples sequentially flowed into the up-flow sedimentation tank. The hydraulic retention time in the settler was approximately $40 \mathrm{~min}$.

In addition, the flocculation section was equipped with an in-situ recognition system as described below, in order to capture in-situ digital particle images. An online 2200PCX particle counter (HACH, USA) and an online turbidimeter (HF, USA) were installed in the sedimentation stage to measure the particle number and effluent turbidity.

\subsection{In-situ recognition system}

An in-situ recognition system was used to capture real-time digital particle images in the flocculation stage (He et al., 2012; Yao et al., 2014). The in-situ recognition technique could obtain the real-time status of floc morphology, avoiding changes of floc structure resulting 
from sampling (Chakraborti et al., 2000). This technique has been successfully used to evaluate the evolution of aggregates during the flocculation process (Chakraborti et al., 2003; Xiao et al., 2011). The obtained digital images were used to calculate the floc size and the fractal dimension.

A schematic of the in-situ recognition system is shown in Fig. 3a. The in-situ recognition technique system consisted of an automated stroboscopic lamp and a computer-controlled high-speed digital charged coupled device (CCD) video camera (SVS-VISTEK GmbH, Germany). The stroboscopic lamp was used to illuminate suspended particles in the flocculation reactor. The camera was installed opposite the lamp in order to offset the backlit shadows of particles. The camera had 992 (horizontal) $\times 510$ (vertical) pixels, and the interrogation window was $4500 \mu \mathrm{m} \times 2310 \mu \mathrm{m}$. A computer was applied to control the camera, as well as store and analyze the particle images.

As shown in Fig. 3b, 9 sites were chosen as CCD camera locations to capture floc images in pool B, pool C, and pool D. 30 images (one image per second) were taken at each CCD camera location to calculate the average floc size and boundary fractal dimension in different experimental conditions. The number of aggregates in different captured images varied from 1000 to 150 , depending on the coagulant dose and the flocculation stage. A decrease in number of aggregates implied the aggregation of small particles.

\subsection{Floc size and boundary fractal dimension}

Floc size is an important parameter of floc morphology. The size of irregularly shaped flocs can be expressed with an equivalent diameter, as described in Eq. (1), where $D$ p represents the floc's equivalent diameter; $A$ is the projected area of a floc.

$$
D_{\mathrm{p}}=(4 A / \pi)^{1 / 2}
$$

The two-dimensional projection boundary fractal dimension $\left(D_{\mathrm{pf}}\right)$ is a statistical quantity to reflect the extent of fill space in fractal flocs (Zhou et al., 2012). In this study, $D_{\text {pf }}$ was used to depict the surface morphology of the flocs, which could effectively reduce the interference 
of self-similarity and scale invariance of aggregates (He and Nan, 2012; Niemeyer et al., 1984; Johnson et al., 1994) . Better than the traditional mass-based fractal dimension, the boundary-based fractal dimension could reflect differences in morphology for flocs having the same mass (Mingli, 2007). Values of $D_{\mathrm{pf}}$ varying from 1 to 2 imply floc projected areas ranging from a sphere shape to a line shape. The boundary fractal dimension was calculated according to Eq. (2), where $D_{\mathrm{pf}}$ is boundary fractal dimension; $P$ is particle perimeter (Mandelbrot et al., 1984).

$$
A \mu P^{2 / D_{p f}}
$$

\section{Result and discussion}

\subsection{Evolution of floc size}

The four pools in the flocculation section separated the flocculation process into four stages. Pool A $\left(\mathrm{G}=548 \mathrm{sec}^{-1}\right)$ performed a coagulation stage where the test water and coagulants were mixed rapidly. Following pool A, flocculation pool B, pool C, and pool D represented changes in the flocculation stage. Fig. 4 indicates the evolution of average floc sizes and the boundary fractal dimensions in flocculation pool B, pool C, and pool D at three different coagulant doses.

As shown in Fig. 4a, at coagulant dose of $1 \mathrm{mg} / \mathrm{L}$ as $\mathrm{Al}$, the average size of flocs first achieved a relatively high value of $62 \mu \mathrm{m}$ in pool B and further slightly increased to around $65 \mu \mathrm{m}$ in pool $\mathrm{C}$; then, the average floc size sharply increased to $78 \mu \mathrm{m}$ in pool $\mathrm{D}$. At coagulant dose of $3 \mathrm{mg} / \mathrm{L}$ as $\mathrm{Al}$, the average size of flocs showed a steady growth trend from around $42 \mu \mathrm{m}$ in pool B to $70 \mu \mathrm{m}$ in pool D. However, the evolution of average floc size presented a different trend under the coagulant dose of $5 \mathrm{mg} / \mathrm{L}$ as Al. The average floc size markedly increased from $48 \mu \mathrm{m}$ in pool B to $65 \mu \mathrm{m}$ in pool $\mathrm{C}$, but remained at $65 \mu \mathrm{m}$ in pool D.

At relatively low coagulant doses ( 1 and $3 \mathrm{mg} / \mathrm{L}$ as $\mathrm{Al}$ ), continuous flocculation occurred continuously from pool B to pool D. At these experimental conditions, charge neutralization played an important role at relatively high mixing intensity $\left(\mathrm{G}=96 \mathrm{sec}^{-1}\right.$ in pool $\mathrm{B}$ and $\mathrm{G}=32$ 
$\sec ^{-1}$ in pool C). These stir rates could effectively promote floc collision, leading to a stable increase in floc size (Colomer et al., 2005). The further decrease of stirring intensity $\left(15 \mathrm{sec}^{-1}\right.$ in pool D) could prevent floc breakage, resulting in an apparent growth of the average flocs size via the sweep floc mechanism (Soos et al., 2008).

However, at a relatively high coagulant dose $(5 \mathrm{mg} / \mathrm{L}$ as $\mathrm{Al})$ a balance of aggregate collision and breakage had been achieved in pool C. The absence of relatively small size flocs and the decrease in the number of flocs reduced the particle collision probability, thereby preventing the growth of flocs in pool D (Moussa et al., 2013).

As a consequence, the evolution trend of the average size of flocs in the different flocculation stages was dependent on both the coagulant dose and the hydraulic conditions. Higher coagulant doses do not result in the formation of bigger flocs, but can achieve flocculation balance more quickly.

\subsection{Evolution of boundary fractal dimension}

Evolution of the boundary fractal dimensions $\left(D_{\mathrm{pf}}\right)$ of flocs was also investigated in the continuous-flow flocculation pool $\mathrm{B}$, pool $\mathrm{C}$, and pool $\mathrm{D}$ at three coagulant doses. The effective $D_{\text {pf }}$ could evaluate the flocs' compaction and effective density. A previous study indicated that the boundary fractal dimension of 1 implied a sphere-shaped aggregate, whereas a fractal dimension of 2 implied a chain-shaped particle (Nan et al., 2009).

Fig. 4b indicates that the values of floc boundary fractal dimension showed slight fluctuations in the three pools. As shown in Fig. 4b, the boundary fractal dimension of aggregates ranged from about 1.14 to 1.20 , which was in agreement with a published study applying a kaolin-humic acid solution as test water (Xiao et al., 2011).

The fractal dimensions of flocs (around $D_{\mathrm{pf}}=1.14$ ) in the three pools at a coagulant dose of $1 \mathrm{mg} / \mathrm{L}$ as $\mathrm{Al}$ were lower than that for the coagulant dose of $5 \mathrm{mg} / \mathrm{L}$ as $\mathrm{Al}$ (around $D_{\mathrm{pf}}$ $=1.20$ ), suggesting that flocs formed at a relatively low coagulant dose were more compact throughout the whole flocculation process. The higher fractal dimension value represented the more irregular shape and rougher surface of the aggregates (Moussa et al., 2013). 
Moreover, at coagulant dosage of $3 \mathrm{mg} / \mathrm{L}$ as $\mathrm{Al}$, the value of the fractal dimension decreased gradually from roughly 1.20 in pool B to 1.15 in pool D. This trend suggests a transition of floc structure from irregular shapes to regular shapes, accompanied by the formation of smoother and more compact flocs. As shown in Fig 4a, the floc size presented an increase trend at the coagulation dosage of $3 \mathrm{mg} / \mathrm{L}$. Both the change in floc size and the fractal dimension at this coagulant dosage imply a good floc growth status.

Therefore, the increase of coagulant doses promoted the generation of more convoluted flocs with more branches, but having lower density. However, this kind of floc structure was too weak to resist the shear rate, leading to the breakage of flocs. These experimental results are comparable to the results shown in Fig. 4a. As a consequence, a relatively low coagulant dose $(1 \mathrm{mg} / \mathrm{L}$ as $\mathrm{Al})$ could generate flocs having higher density, which contributed to the formation of bigger flocs when the testing water sequentially flowed through the three pools. However, a relatively high coagulant dose $(5 \mathrm{mg} / \mathrm{L}$ as $\mathrm{Al})$ led to the formation of less compact and more branched flocs, resulting in the restriction of floc growth.

\subsection{Flocs size distributions}

Fig. 5 shows the cumulative floc size distributions in flocculation pool B, pool C, and pool D at three different coagulant doses. As presented in Fig. 5, the floc size distributions presented the same pattern in the three pools at coagulant dosage of $5 \mathrm{mg} / \mathrm{L}$ as $\mathrm{Al}$, suggesting the floc size entered a steady stage at the beginning of flocculation in pool B. However, at $3 \mathrm{mg} / \mathrm{L}$ of coagulant, the proportion of floc size less than $100 \mu \mathrm{m}$ declined from roughly $86 \%$ in pool B to roughly $81 \%$ in pool $\mathrm{D}$, implying that the frequency of small size flocs appeared to decrease during the three sequential flocculation stages. Furthermore, a similar trend was observed at the coagulant dose of $1 \mathrm{mg} / \mathrm{L}$ as $\mathrm{Al}$. These results indicated that aggregation was occurring in the entire continuous-flow flocculation stage at relatively low coagulant doses (1 $\mathrm{mg} / \mathrm{L}$ and $3 \mathrm{mg} / \mathrm{L}$ as $\mathrm{Al}$ ), supporting the earlier discussion in Section 2.1.

In addition, the cumulative percentage of small size flocs (less than $100 \mu \mathrm{m})$ in pool D with $1 \mathrm{mg} / \mathrm{L} \mathrm{PACl}$ dose (76\%) was less than that for the $5 \mathrm{mg} / \mathrm{L} \mathrm{PACl}$ dose (85\%), suggesting 
that a relatively low coagulant dose may produce more large flocs via electrostatic and bridging mechanisms. This result was in good agreement with the evolution of floc size, as discussed in Section 2.1. Consequently, it is speculated that flocs formed under relatively low coagulant doses were able to gradually grow into large flocs through a series of flocculation processes.

\subsection{Floc eccentricity ratios}

The eccentricity ratio refers to the ratio of an aggregate's short axis and long axis, and can represent the irregularity of flocs (Meng et al., 2015). A value approaching 1 indicates flocs with a spherical shape, and conversely, a value close to 0 indicates a chain structure. Fig. 6 illustrates the floc eccentricity ratios at different coagulant doses in flocculation pool B, pool C, and pool D. A pattern of normal distribution of the eccentricity ratios was observed at all three coagulant dosages. At the coagulant dose of $5 \mathrm{mg} / \mathrm{L}$ as $\mathrm{Al}$, the eccentricity ratios of flocs were concentrated in the range 0.3 to 0.5 , indicating that chain-shaped flocs dominated in the entire flocculation process at this relatively high coagulant dose. At coagulant dose of $3 \mathrm{mg} / \mathrm{L}$ as $\mathrm{Al}$, the eccentricity ratio of 0.5 accounted for a large proportion in all the flocculation pools. In addition, the presence of eccentricity ratios close to 1 increased at the coagulant dose of $1 \mathrm{mg} / \mathrm{L}$ as $\mathrm{Al}$, compared with the higher coagulants doses ( 3 and $5 \mathrm{mg} / \mathrm{L}$ as $\mathrm{Al}$ ).

At coagulant doses of 1 and $3 \mathrm{mg} / \mathrm{L}$ as $\mathrm{Al}$, the eccentricity ratio (ranging from 0.8 to 0.9 in pool D) was apparently higher than that in pool B and C, suggesting that flocs changed to a spherical shape and became more compact during the flocculation process at relatively low coagulant doses. These results are consistent with the former analysis on floc size evolution and distribution. It can be concluded that a relatively high coagulant dose $(5 \mathrm{mg} / \mathrm{L}$ as $\mathrm{Al})$ is much more inclined to generate chain-shaped and lower density flocs in pool B, resulting in the restriction of flocs' further growth in pool C and pool D.

\subsection{Floc morphology}


Fig. 7 shows the evolution of floc morphology captured by the in-situ recognition system at the coagulant dose of $3 \mathrm{mg} / \mathrm{L}$ as $\mathrm{Al}$. The floc size gradually increased with the test water continuously flowing from pool B to pool D. These changes in floc morphology were consistent with the evolution of floc size described in Section 2.1.

In flocculation pool $\mathrm{B}$, a relatively high shear rate $\left(\mathrm{G}=96 \mathrm{sec}^{-1}\right)$ promoted particle collision and aggregation, resulting in the formation of small and compact flocs in this flocculation stage. Based on the floc morphology, it is speculated that the flocs formed mainly via a charge neutralization mechanism in pool B. Then, the decrease of shear rate in pool $\mathrm{C}$ and pool D had a beneficial effect on aggregation of floc fragments, forming more branched structure flocs in pool C. Moreover, the larger particles aggregated in pool D by the bridge mechanism.

\subsection{Comparison of the inclined plates and V-shaped plates}

Table 1 shows the number of particles in the traditional inclined plate settler and the V-shaped plate settler at the coagulant dose of $1 \mathrm{mg} / \mathrm{L}$ as $\mathrm{Al}$. In unit $\mathrm{E}$, the particle numbers in the two settlers were similar because of the similar structures in this unit. The small size particles (less than $5 \mu \mathrm{m}$ ) were dominant, whereas flocs with size larger than $8 \mu \mathrm{m}$ were scarcely observed due to rapid sedimentation of relatively large flocs.

In unit $\mathrm{F}$, the application of the two kinds of plates resulted in a significant difference in the particle numbers. The total floc number in the inclined plate settler was greater than that in the V-shaped plate settler, suggesting better sedimentation efficiency for the V-shaped settler. In unit $\mathrm{F}$, the $\mathrm{V}$-shaped plate region had apparently fewer small size flocs (less than 5 $\mu \mathrm{m})$, but more relatively large size flocs, compared with the inclined plate region. The number of small size flocs (less than $5 \mu \mathrm{m}$ ) in the inclined plate section was $8268 \pm 322$, which was nearly twice the number in the V-shaped plate section, $4721 \pm 124$.

These results indicate that the conventional inclined plates were ineffective for sedimentation of relatively small size floc, which has been reported by a previous study (Adelman et al., 2013). However, the V-shaped plate had a positive effect on the removal of 
relatively small size flocs (less than $5 \mu \mathrm{m}$ ), owing to the re-aggregation that took place in the V-shaped region. As shown in Fig. 2, the V-shaped plate not only possessed the properties of the inclined plate, but also added a V-shaped region as a miniature folded-plate flocculation tank. Therefore, the small size flocs probably collided and restructured in this region (Jarvis et al., 2005). The re-flocculation process resulted in the formation of stronger and more compact aggregates that tend to precipitate (Parsapour et al., 2014). Furthermore, due to the effective sedimentation in the $\mathrm{V}$-shaped region, the total floc amount in unit $\mathrm{G}$ of the V-shaped settler was obviously less than that for the inclined plate, implying a better sedimentation efficiency for the V-shaped settler.

\subsection{Effluent turbidity of the continuous-flow reactor}

Fig. 8 presents the effluent turbidity for the traditional inclined plates and the novel V-shaped plates. As shown in Fig. 8, the sedimentation efficiency was coagulant dosage dependent. An apparent reduction of effluent turbidity was observed in both settler units as coagulant dosages increased from 0.5 to $2.0 \mathrm{mg} / \mathrm{L}$ as $\mathrm{Al}$. In this range of coagulant doses, the V-shaped plates presented higher turbidity removal efficiency than the inclined plates. The effluent turbidity showed the same trend at coagulant doses ranging from 3.0 to $5.0 \mathrm{mg} / \mathrm{L}$ as $\mathrm{Al}$ in both the V-shaped plate sedimentation and the inclined plate sedimentation. Based on the former analysis, the V-shaped plate could effectively precipitate relatively small size flocs via re-flocculation at the V-shaped structure. Therefore, the V-shaped plate settler presented a better precipitation rate than the inclined plate settler at relatively low coagulant doses.

\section{Conclusions}

This study investigated the evolution of floc morphology in a continuous-flow flocculation and sedimentation reactor. The results of floc size investigations indicated that the floc evolution in different flocculation pools was coagulant dose dependent. The value of boundary fractal dimension increased from 1.14 at $1 \mathrm{mg} / \mathrm{L} \mathrm{PACl}$ dose to 1.20 at $5 \mathrm{mg} / \mathrm{L} \mathrm{PACl}$ dose, illustrating that a linear shape floc tended to be produced at a relatively low coagulant 
dose, whereas a spherical shape tended to be generated at a relatively high coagulant dose. The results for floc size distribution were in a good agreement with the average floc size results. The eccentricity ratio of aggregates mainly ranged from 0.3 to 0.6 , suggesting that flocs with elliptical shapes were dominant in the entire flocculation process, which was supported by the results obtained in the fractal dimension analysis. Floc morphology measurements appeared to show a sustained growth of aggregates in the entire flocculation process at the coagulant dose of $3 \mathrm{mg} / \mathrm{L}$ as $\mathrm{Al}$, which was consistent with the evolution of average floc size. It can be concluded that flocs maintained sustained growth at relatively low coagulant doses throughout the entire flocculation reactor, whereas the floc growth could be restricted when coagulant doses were excessive. Consequently, at relatively low PACl doses $(1 \mathrm{mg} / \mathrm{L}$ or $3 \mathrm{mg} / \mathrm{L})$, small and compact aggregates were formed by charge neutralization in pool B; then, flocs further grew in pool C and pool D by a sweep floc mechanism.

A traditional inclined plate settler and a $\mathrm{V}$-shaped plate settler were investigated in the precipitation section. The experimental results indicated that the inclined plates were effective for the removal of relatively large size particles, whereas the V-shaped plates had advantages in the sedimentation of small size aggregates. The V-shaped plates provided a region for restructuring of aggregates and promoted the formation of more compact and larger aggregates, thereby decreasing the particle number and reducing the effluent turbidity. As a result, the V-shaped plate settler may be an alternative method to improve sedimentation efficiency.

\section{Acknowledgments}

This research was supported by the National Science and Technology Major Project of Twelfth Five Years (Nos. 2014ZX07201-012-2, 2013ZX07201007-002), the National Innovation Team supported by the National Science Foundation of China (No. 50821002), and the State Key Laboratory of Urban Water Resource and Environment (Harbin Institute of Technology) (No. 2012DX07). 


\section{References}

Adelman M. J., Hurst M. W., Weber-Shirk M. L., Cabrito T. S., Somogyi C., Lion L. W., 2013. Floc roll-up and its implications for the spacing of inclined settling devices. Environ. Eng. Sci.. 30(6), 302-310.

Becker V., Schlauch E., Behr M., Briesen H., 2009. Restructuring of colloidal aggregates in shear flows and limitations of the free-draining approximation. J. Colloid Interf. Sci. $339(2), 362-372$.

Chakraborti R. K., Atkinson J. F., Van Benschoten J. E., 2000. Characterization of alum floc by image analysis. Environ. Sci. Technol. 34(18), 3969-3976.

Chakraborti R. K., Gardner K. H., Atkinson J. F., Van Benschoten J. E., 2003. Changes in fractal dimension during aggregation. Water Res. 37(4), 873-883.

Colomer J., Peters F., MarraséC., 2005. Experimental analysis of coagulation of particles under low-shear flow. Water Res. 39(13), 2994-3000.

Gmachowski L., 2009. Aggregate restructuring by internal aggregation. Colloid Surf. A-Physicochem. Eng. Asp. 352(1-3), 70-73.

He W., Nan J., 2012. Characteristic analysis on morphological evolution of suspended particles in water during dynamic flocculation process. Desalin. Water Treat. 41(1-3), 26-34.

He W., Nan J., Li H., Li S., 2012. Characteristic analysis on temporal evolution of floc size and structure in low-shear flow. Water Res. 46(2), 509-520.

Hua B., Xiong H., Wang Z., Yang J., Zhang S., Wang Z., Deng B., 2014. Physico-chemical processes. Water Environ. Res. 86(10). 992-1025.

Jarvis P., Jefferson B., Gregory J., Parsons S. A., 2005. A review of floc strength and breakage. Water Res. 39(14), 3121-3137.

Johnson C. P., Li X., Logan B. E., 1996. Settling velocities of fractal aggregates. Environ. Sci. Technol. 30(6), 1911-1918.

Kim J. H., Lee C. H., Lee E. J., Lee K. H., Kwon S. B., Park H.-S., Kim H. S., Jang A., 2013. The effect of re-aggregated floc by additional coagulant on membrane. J. Taiwan Inst. 
Chem. E. 44(5), 802-807.

Li R., Gao B., Huang X., Dong H., Li X., Yue Q., Wang Y., Li Q., 2014. Compound bioflocculant and polyaluminum chloride in kaolin-humic acid coagulation: Factors influencing coagulation performance and floc characteristics. Bioresource Technol. $172,8-15$.

Mandelbrot B. B., Passoja D. E., Paullay A. J., 1984. Fractal character of fracture surfaces of metals. Nat. 308, 721-722.

Meng X., Wu H., Morbidelli M., 2015. Kinetics and cluster morphology evolution of shear-driven aggregation of well-stabilized colloids. Langmuir, 31(3), 1113-1119.

Wang M., 2007. Analysis of Cement Flocculation Combining with Fractal Theory. Journal of Shenyang Jianzhu University (Natural Science). 1, 019.

Moussa A. S., Lattuada M., Conchúir B. n. O., Zaccone A., Morbielli M., Soos M., 2013. Flow-induced aggregation and breakup of particle clusters controlled by surface nanoroughness. Langmuir, 29(47), 14386-14395.

Nan J., He W., Song J., Song X., 2009. Fractal growth characteristics of flocs in flocculation process in water treatment. Energ. Environ. Technol. 2, 582-588.

Nan J., Li H. Y., He W. P., 2011. Fractal dimension of floc growth in micro-coagulation stage I: using to forecast water quality of settled water. Adv. Mater. Res. 243, 4831-4834.

Nasser M., 2014. Characterization of floc size and effective floc density of industrial papermaking suspensions. Sep. Purif. Technol. 122, 495-505.

Niemeyer L., Pietronero L., Wiesmann H., 1984. Fractal dimension of dielectric breakdown. Phys. Rev. Lett. 52(12), 1033-1036.

Parsapour G. A., Hossininasab M., Yahyaei M., Banisi S., 2014. Effect of settling test procedure on sizing thickeners. Sep. Purif. Technol. 122(10), 87-95.

Shin G.-A., Sobsey M. D., 2015. Removal of norovirus from water by coagulation, flocculation and sedimentation processes. Water Sci. Tech-W. Sup. 15(1), 158-163.

Soos M., Moussa A. S., Ehrl L., Sefcik J., Wu H., Morbidelli M., 2008. Effect of shear rate on aggregate size and morphology investigated under turbulent conditions in stirred 
tank. J. Colloid Interf. Sci. 319(2),577-589.

Vaezi F., Sanders R. S., Masliyah J. H., 2011. Flocculation kinetics and aggregate structure of kaolinite mixtures in laminar tube flow. J. Colloid Interf. Sci. 355(1), 96-105.

Vandamme D., Muylaert K., Fraeye I., Foubert I., 2014. Floc characteristics of Chlorella vulgaris: influence of flocculation mode and presence of organic matter. Bioresource Technol. 151, 383-387.

Wang D., Wu R., Jiang Y., Chow C. W., 2011. Characterization of floc structure and strength: Role of changing shear rates under various coagulation mechanisms. Colloid Surf. A-Physicochem. Eng. Asp. 379(1-3), 36-42.

Xiao F., Lam K., Li X., Zhong R., Zhang X., 2011. PIV characterisation of flocculation dynamics and floc structure in water treatment. Colloid Surf. A-Physicochem. Eng. Asp. 379(1-3), 27-35.

Yang Z., Wu H., Yuan B., Huang M., Yang H., Li A., Bai J., Cheng R., 2014. Synthesis of amphoteric starch-based grafting flocculants for flocculation of both positively and negatively charged colloidal contaminants from water. Chem. Eng. J. 244, 209-217.

Yao M., Nan J., Chen T., 2014. Effect of particle size distribution on turbidity under various water quality levels during flocculation processes. Desalination. 354, 116-124.

Yao M., Nan J., Li Q., Zhan D., Chen T., Wang Z., Li H., 2015. Effect of under-dosing coagulant on coagulation-ultrafiltration process for treatment of humic-rich water with divalent calcium ion. J. Membrance Sci. 495, 37-47.

Yao M., Nan J., Chen T., Zhan D., Li Q.,Wang Z., Li H., 2015. Influence of flocs breakage process on membrane fouling in coagulation/ultrafiltration process-Effect of additional coagulant of poly-aluminum chloride and polyacrylamide. J. Membrance Sci. 491, 63-72.

Yu W., Gregory J., Campos L. C., 2011. Breakage and re-growth of flocs: Effect of additional doses of coagulant species. Water Res. 45(20), 6718-6724.

Zhao Y., Phuntsho S., Gao B., Huang X., Qi Q., Yue Q., Wang Y., J.-H. Kim, Shon H., 2013. Preparation and characterization of novel polytitanium tetrachloride coagulant for 
water purification. Environ. Sci. Technol. 47(22), 12966-12975.

Zhou D., Dong S., Gao L., Ju R., Niu S., 2012. Effect of double-stage velocity gradients on abatement and morphology characteristics of flocs in a conical fluidized-bed flocculator. Sep. Purif. Technol. 98, 383-388.

\section{List of table}

Table 1 Number of particles in different unit of the inclined plate settler and the V-shape plate settler (coagulant dose $1 \mathrm{mg} / \mathrm{L}$ as $\mathrm{Al}$ )

\section{List of figures}

Fig. 1 Schematic of the continual-flow reactor involving flocculation section and sedimentation section.

Fig. 2 Sectional view of two plate settlers installed in the unit F: (a) a V-shape plate and (b) a traditional inclined plate

Fig.3 Schematic of (a) the in-situ recognition system, and (b) the CCD camera locations at pool B, pool C, and pool D

Fig. 4 Variation of floc average size (a) and boundary fractal dimension (b) at different coagulants doses $(1 \mathrm{mg} / \mathrm{L}$ as $\mathrm{Al}, 3 \mathrm{mg} / \mathrm{L}$ as $\mathrm{Al}, 5 \mathrm{mg} / \mathrm{L}$ as $\mathrm{Al})$ in the pool $\mathrm{B}$, pool $\mathrm{C}$ and pool D Fig. 5 Comparison of floc size distributions in the three flocculation pools at coagulant dosages at (a) $5 \mathrm{mg} / \mathrm{L}$ as $\mathrm{Al}$, (b) $3 \mathrm{mg} / \mathrm{L}$ as $\mathrm{Al}$, (c) $1 \mathrm{mg} / \mathrm{L}$ as $\mathrm{Al}$, (pool B, pool C and pool D as described in Fig. 1)

Fig. 6 Comparison of particle eccentricity ratios in the three flocculation pools at coagulant dosages at (a) $5 \mathrm{mg} / \mathrm{L}$ as Al, (b) $3 \mathrm{mg} / \mathrm{L}$ as $\mathrm{Al}$, (c) $5 \mathrm{mg} / \mathrm{L}$ as $\mathrm{Al}$, (pool B, pool C and pool D as described in Fig. 1)

Fig. 7 Floc morphology of (a) flocculation pool B, (b) flocculation pool C, and (c) flocculation pool D, (coagulant dose $3 \mathrm{mg} / \mathrm{L}$ as $\mathrm{Al}$ )

Fig. 8 Comparison of effluent turbidity of the inclined plate settler and the V-shape plate settler 
JES-D-16-00304-Table

Table 1 Number of particles in different unit of the inclined plate settler and the V-shape plate settler (coagulant dose $1 \mathrm{mg} / \mathrm{L}$ as Al)

\begin{tabular}{lllllll}
\hline \multirow{2}{*}{ Flocs size } & \multicolumn{4}{l}{ Particle amount $\quad$ (number/mL) } \\
\cline { 2 - 7 } & \multicolumn{2}{l}{ Inclined plate settler } & \multicolumn{3}{l}{ V-shape plate settler } \\
\cline { 2 - 7 } & unit E & unit $\mathrm{F}$ & unit $\mathrm{G}$ & unit $\mathrm{E}$ & unit $\mathrm{F}$ & unit $\mathrm{G}$ \\
\hline$<5 \mu \mathrm{m}$ & $4782 \pm 126$ & $8268 \pm 322$ & $1932 \pm 58$ & $5033 \pm 199$ & $4721 \pm 124$ & $444 \pm 18$ \\
$5-8 \mu \mathrm{m}$ & $545 \pm 22$ & $971 \pm 59$ & $243 \pm 25$ & $501 \pm 29$ & $2143 \pm 80$ & $33 \pm 4$ \\
$>8 \mu \mathrm{m}$ & $4 \pm 1$ & $20 \pm 3$ & $1 \pm 1$ & $4 \pm 1$ & $195 \pm 17$ & $3 \pm 1$ \\
\hline
\end{tabular}




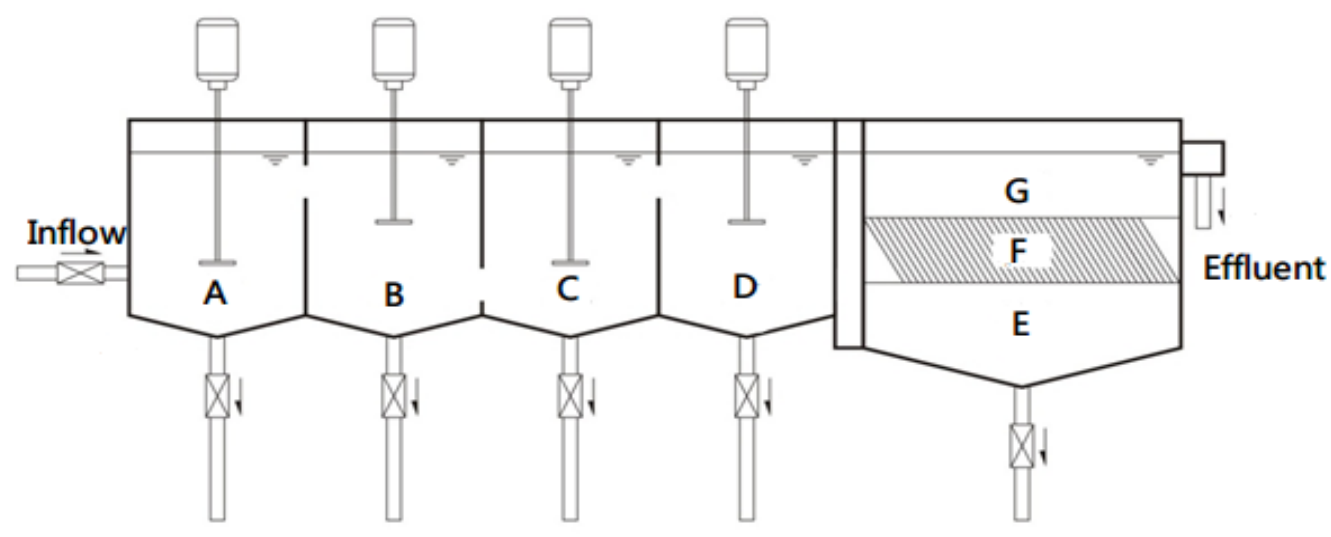

Fig. 1 Schematic of the continual-flow reactor involving flocculation section and sedimentation section.
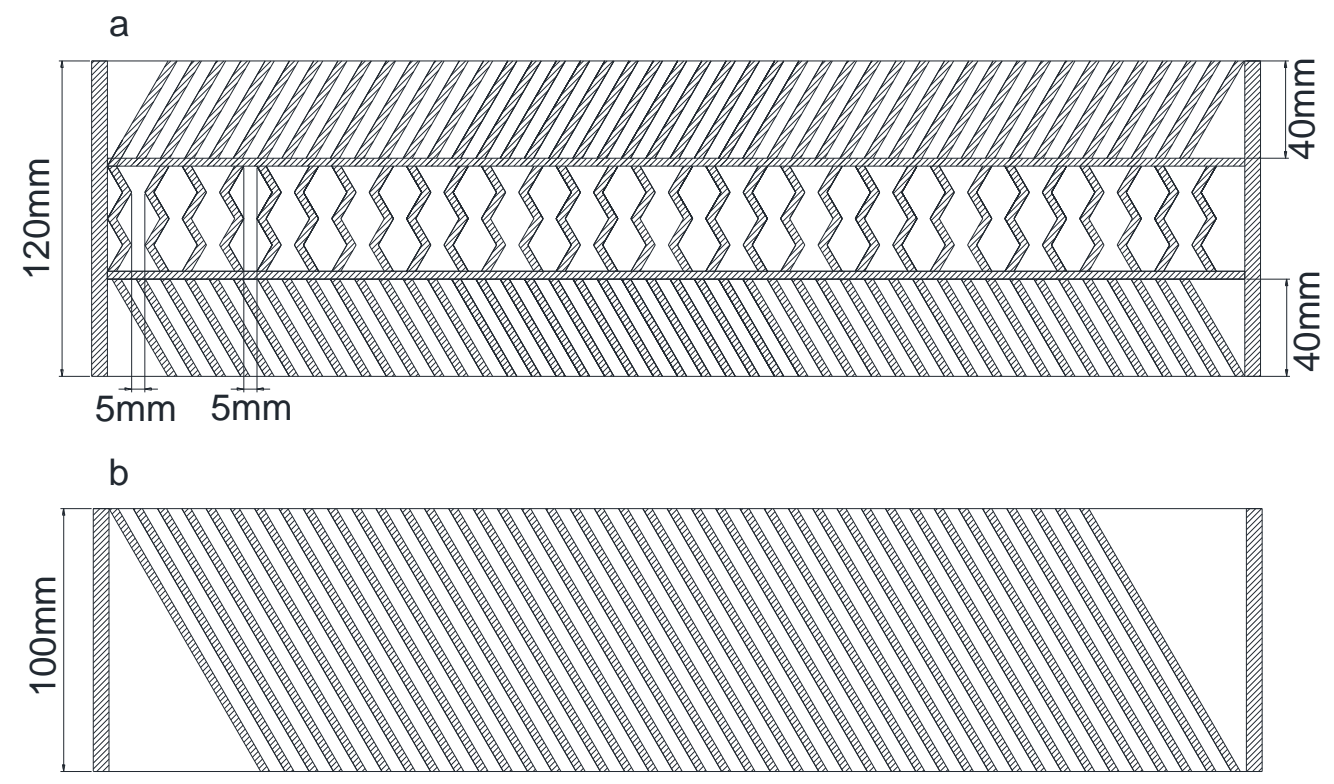

Fig. 2 Sectional view of two plate settlers installed in the unit F: (a) a V-shape plate and (b) a traditional inclined plate 


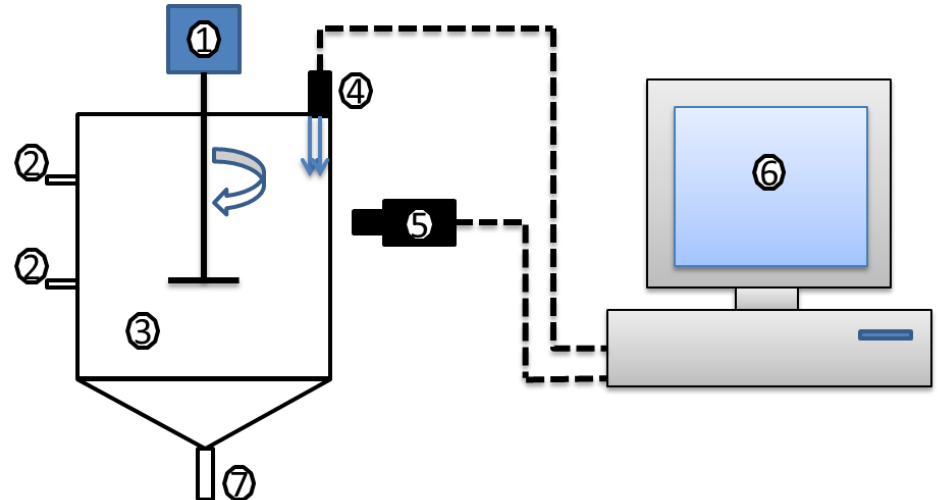

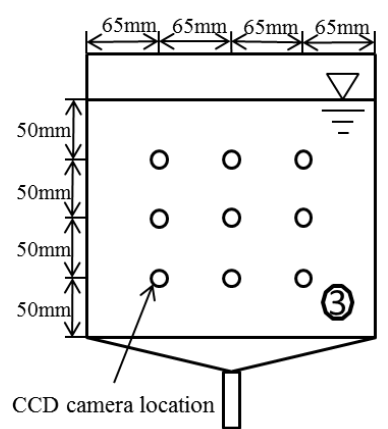

b

1 Agitator ; 2 Sample point; 3 Flocculation tank; 4 Light source; 5 CCD camera; 6 Computer; 7 Mud

Fig. 3 Schematic of (a) the in-situ recognition system, and (b) the CCD camera locations at pool B, pool C, and pool D
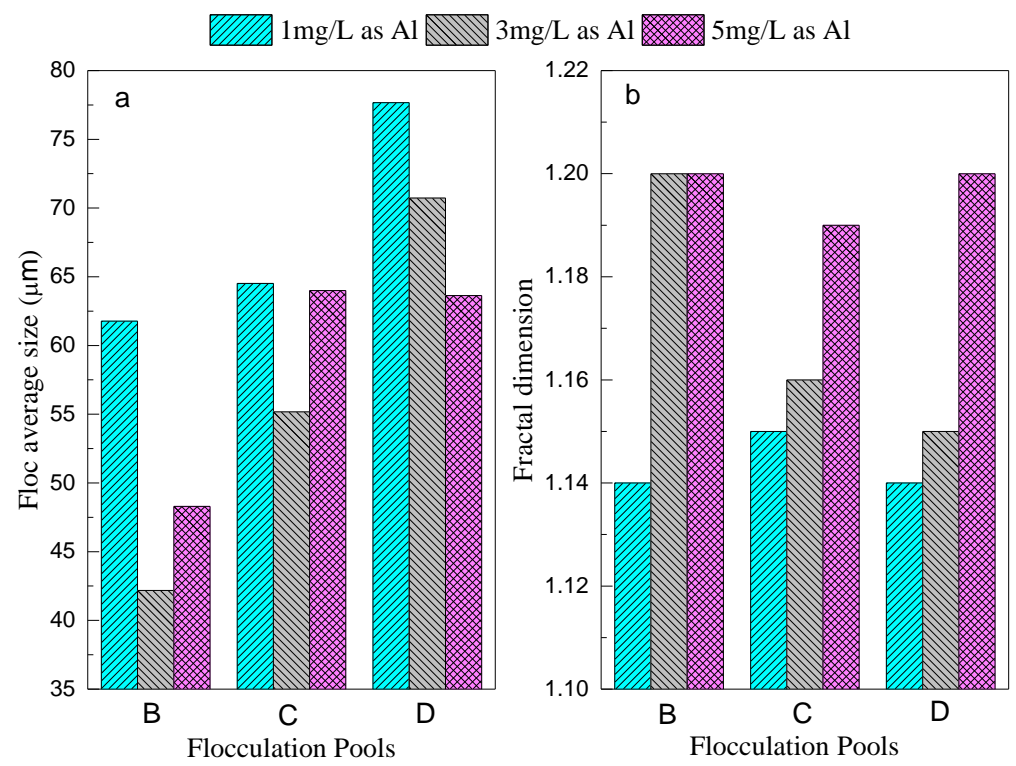

Fig. 4 Variation of floc average size (a) and boundary fractal dimension (b) at different coagulants doses $(1 \mathrm{mg} / \mathrm{L}$ as $\mathrm{Al}, 3 \mathrm{mg} / \mathrm{L}$ as $\mathrm{Al}, 5 \mathrm{mg} / \mathrm{L}$ as $\mathrm{Al})$ in the pool $\mathrm{B}$, pool C and pool D 


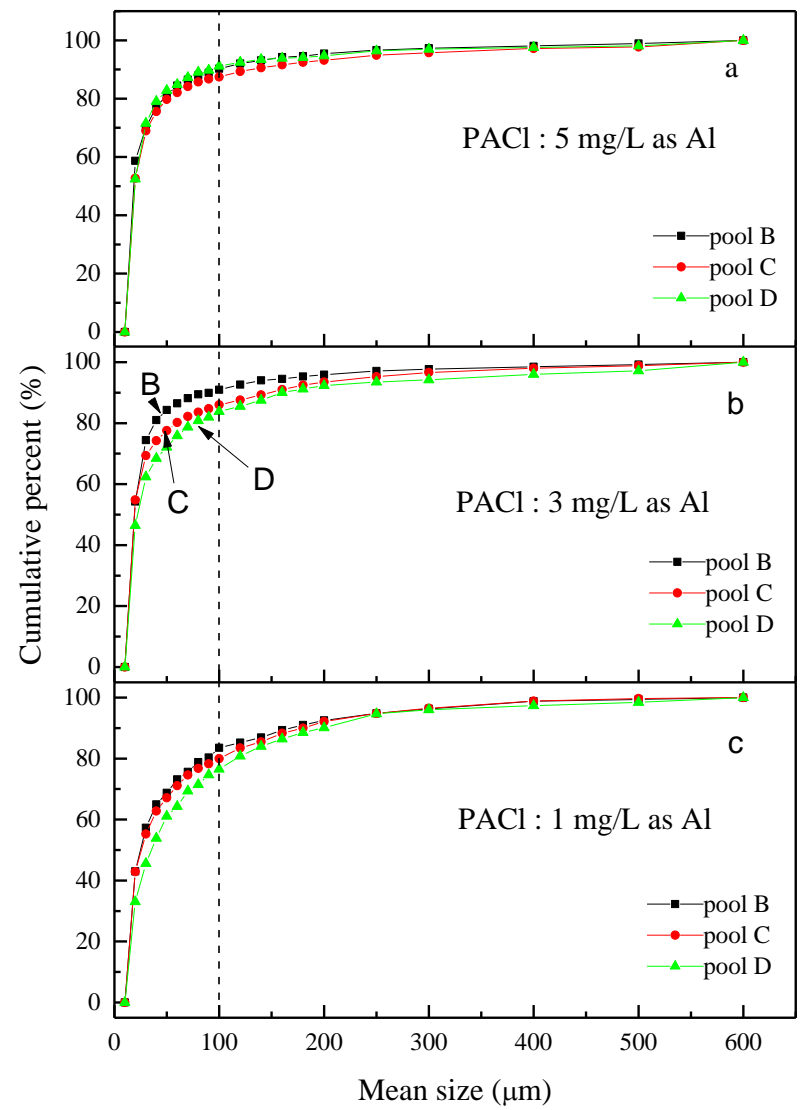

Fig. 5 Comparison of floc size distributions in the three flocculation pools at coagulant dosages at (a) $5 \mathrm{mg} / \mathrm{L}$ as $\mathrm{Al}$, (b) $3 \mathrm{mg} / \mathrm{L}$ as $\mathrm{Al}$, (c) $1 \mathrm{mg} / \mathrm{L}$ as $\mathrm{Al}$, (pool B, pool C and pool D as described in Fig. 1) 


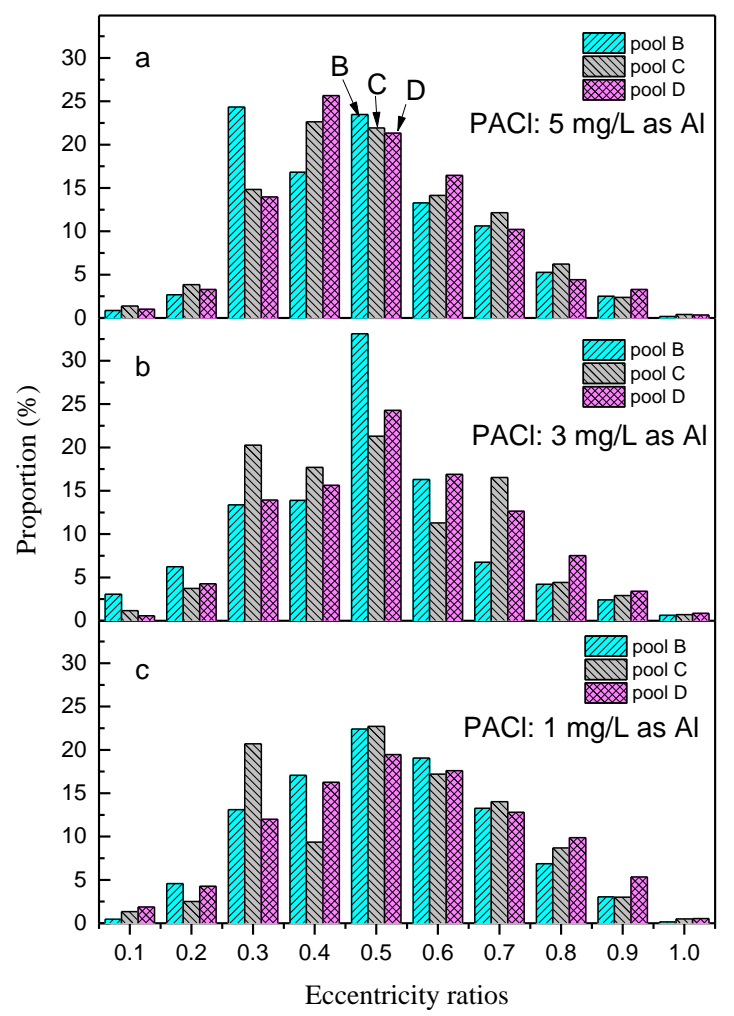

Fig. 6 Comparison of particle eccentricity ratios in the three flocculation pools at coagulant dosages at (a) $5 \mathrm{mg} / \mathrm{L}$ as $\mathrm{Al}$, (b) $3 \mathrm{mg} / \mathrm{L}$ as $\mathrm{Al}$, (c) $5 \mathrm{mg} / \mathrm{L}$ as $\mathrm{Al}$, (pool B, pool C and pool D as described in Fig. 1)

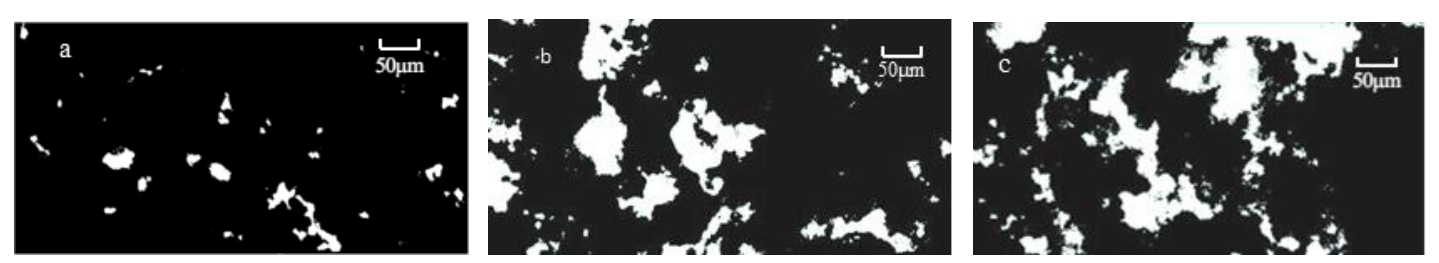

Fig. 7 Floc morphology of (a) flocculation pool B, (b) flocculation pool C, and (c) flocculation pool D, (coagulant dose $3 \mathrm{mg} / \mathrm{L}$ as $\mathrm{Al}$ ) 


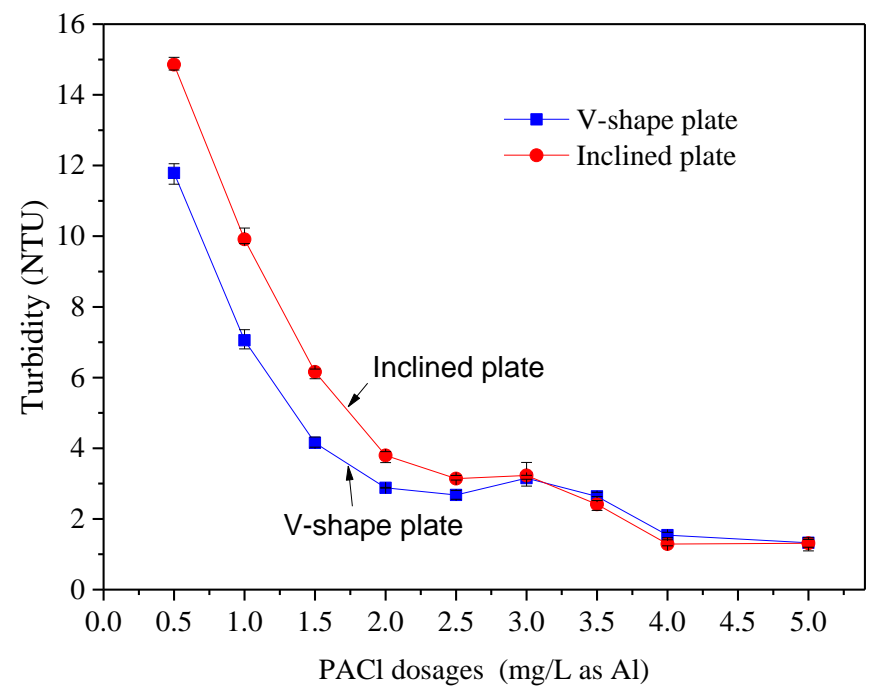

Fig. 8 Comparison of effluent turbidity of the inclined plate settler and the V-shape plate settler 